\title{
ENHANCING PEDESTRIAN SAFETY THROUGH THE DEVELOPMENT OF ADVANCED OPERATIONAL STRATEGIES FOR CROSSWALKS IN RESIDENTIAL AREAS
}

\author{
Qinaat Hussain, Wael Alhajyaseen, Mohamed Kharbeche
}

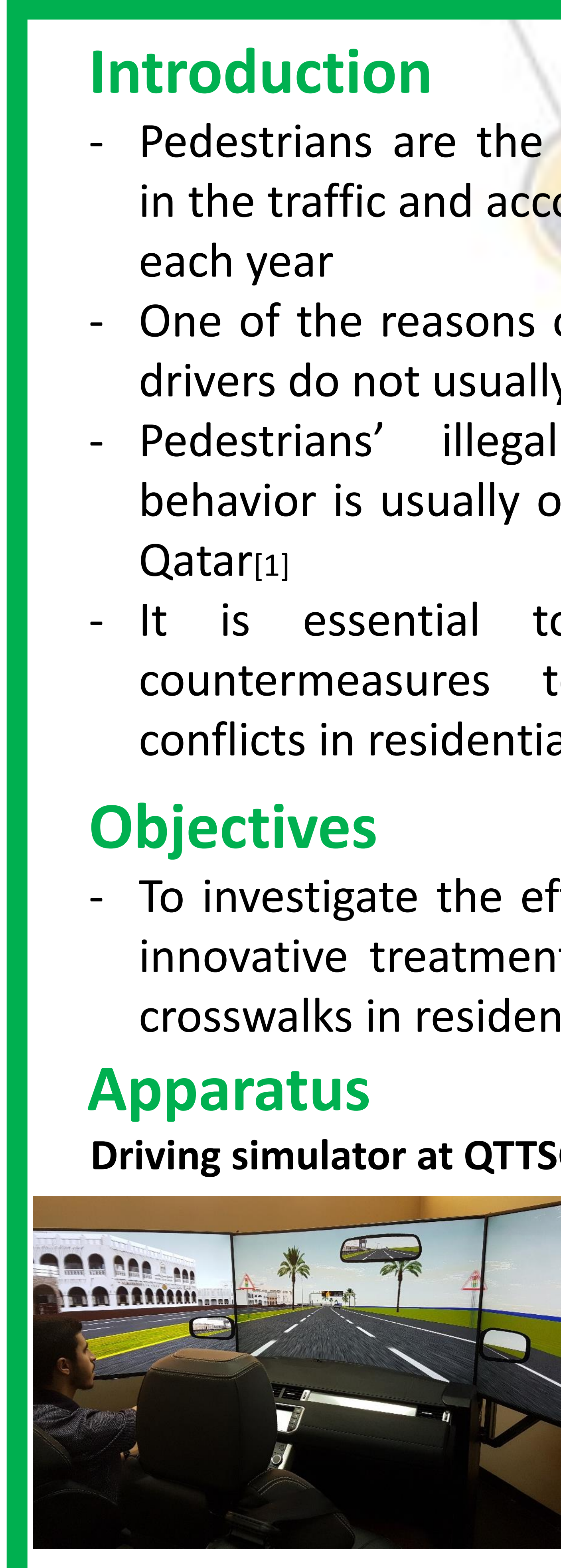

$135^{\circ}$ horizontal view $5760 \times 1080$ pixels resolution

Participants

58 participants with a valid Qatari driving license

- $84.5 \%$ Male vs $\mathbf{1 5 . 5 \%}$ Female

$41 \%$ Asians, 51\% Africans, 3.4\% Americans, 3.4\% Europeans

Mean age: 26.69 years (SD: 6.9 )

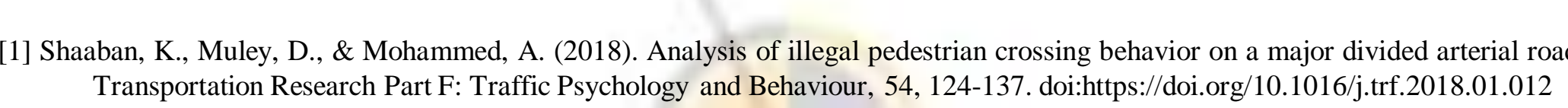

\section{STUDY DESIGN}

\section{Control 6 scenarios}

- Typical crosswalk in residential areas in Doha City

- Untreated - only with the default static signs

2 LED light units

- Flashing yellow lights in the absence of pedestrians

- Flashing red lights upon the pedestrian detection

3 Variable message sign

- SLOW message in case of no pedestrian

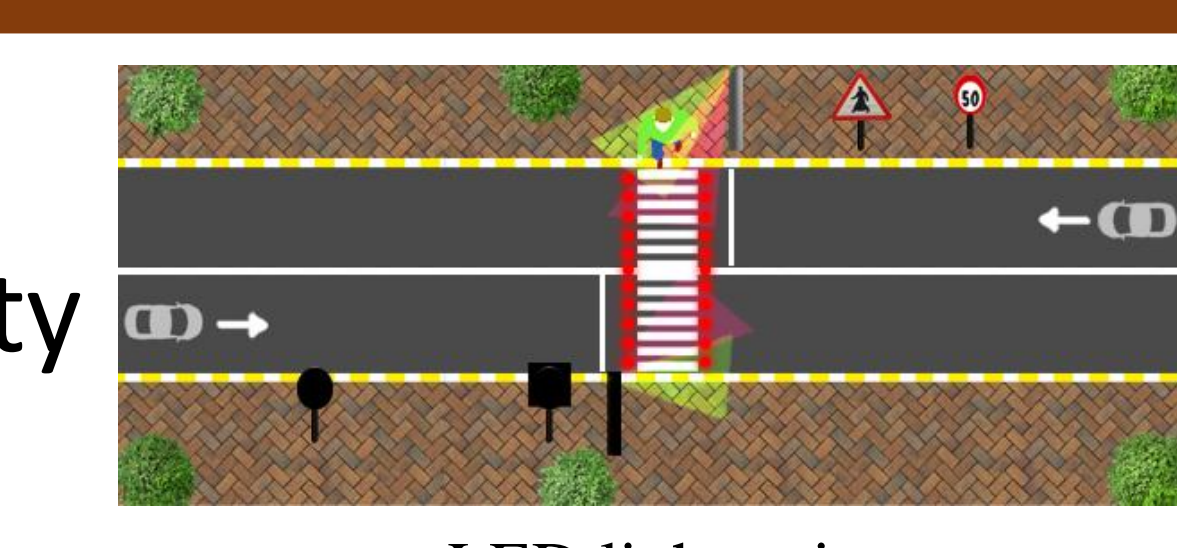

LED light units

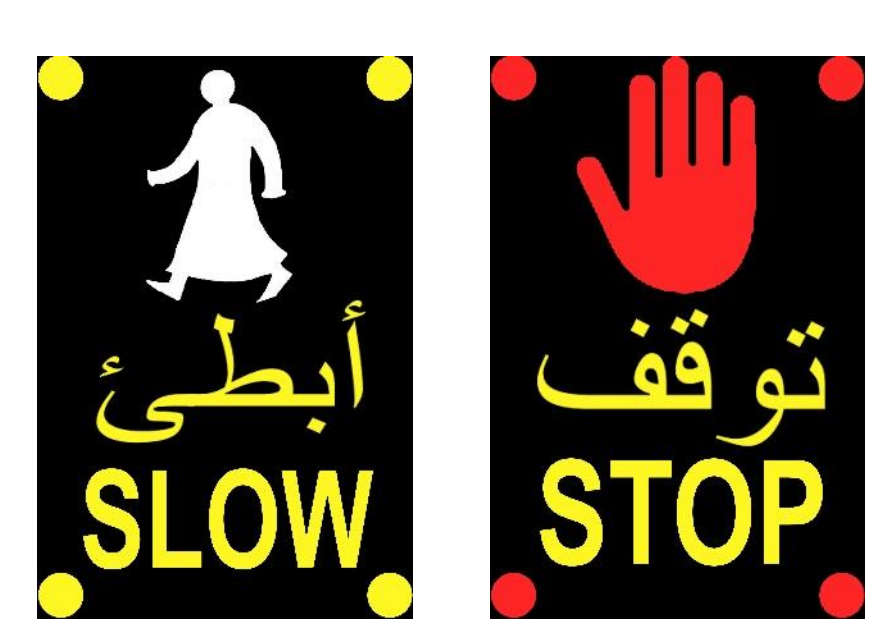

SLOW STOP
- Change to STOP message with animations upon the pedestrian detection
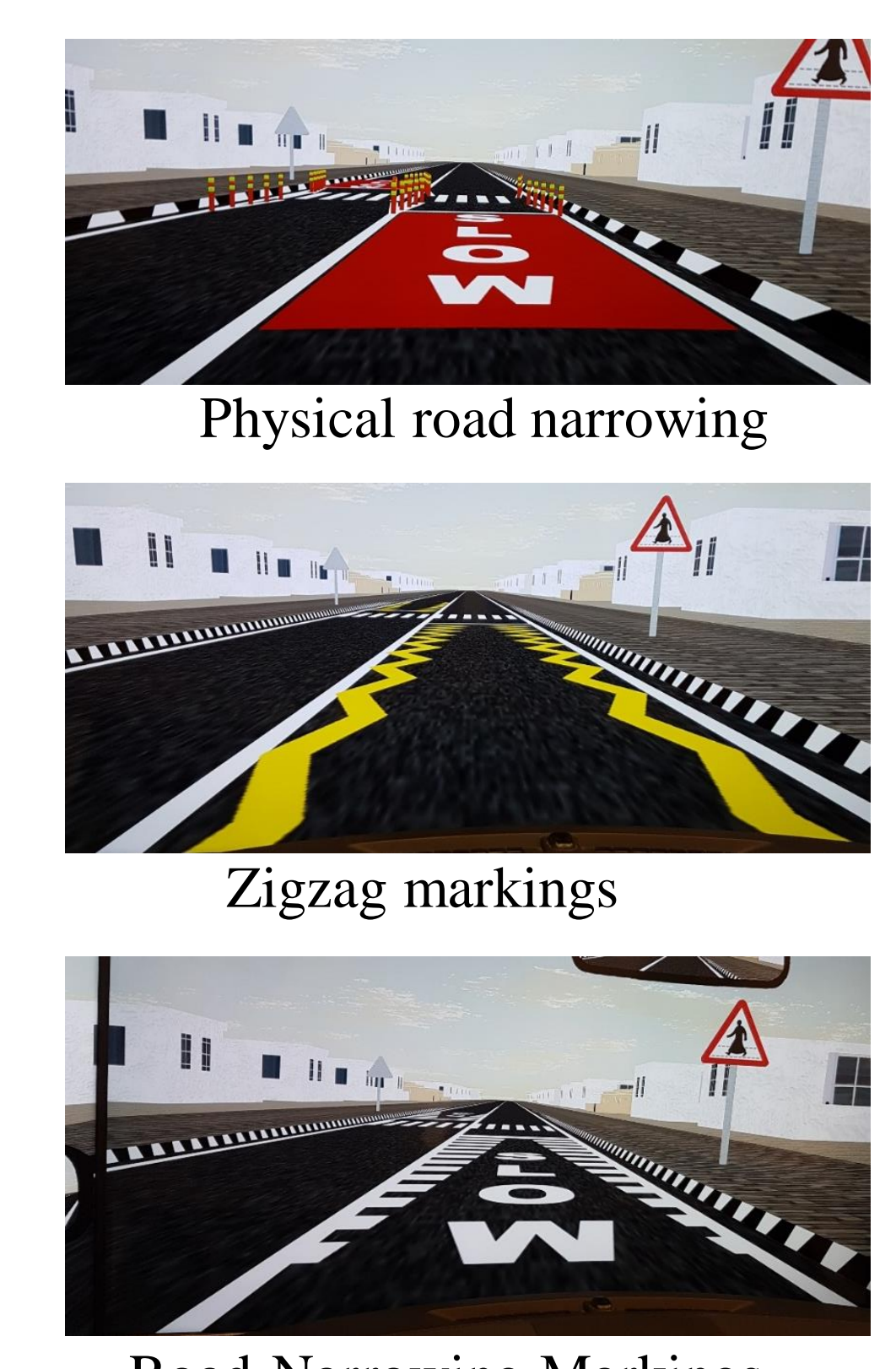

4 Physical road narrowing

- Red pavement showing the message "SLOW"

- Barriers - narrowing the lane from both sides

5 Zigzag Markings

- Yellow zigzag markings

- V-shaped loops in the drivers' direction

6 Road narrowing Markings

- Based on Japanese manual on pedestrian safety

- SLOW word in the V-shaped loop
Main findings

\section{Recommendations}

\begin{tabular}{|l|l|l|}
$83.6 \%$ & $4.47 \mathrm{~s}$ & Least effective
\end{tabular}

$94.5 \%$

$6.83 \mathrm{~s}$
Effective

$98.2 \%$

$7.49 \mathrm{~s}$

Effective

$98.2 \%$

$5.12 \mathrm{~s}$

Most effective

$5.06 \mathrm{~s}$

Effective

$5.20 \mathrm{~s}$

Effective

\section{Best Performance:}

VMS and Physical

VMS and Physical are recommended as a potentially effective

- By improving yielding rates

- By reducing vehicle-pedestrian conflicts

- By motivating drivers to reduce their speed

\section{CONCLUSION}

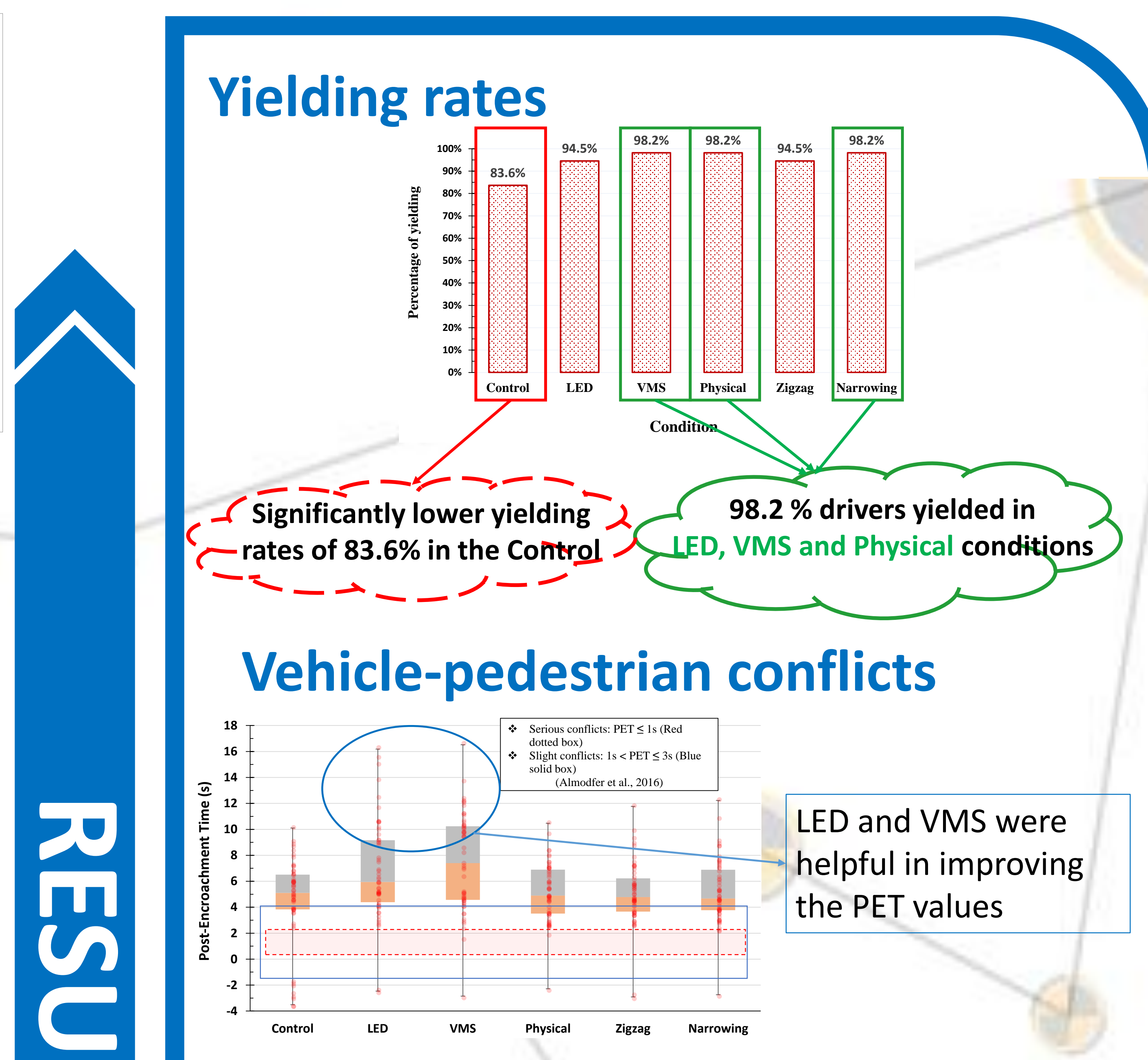

Mean speed

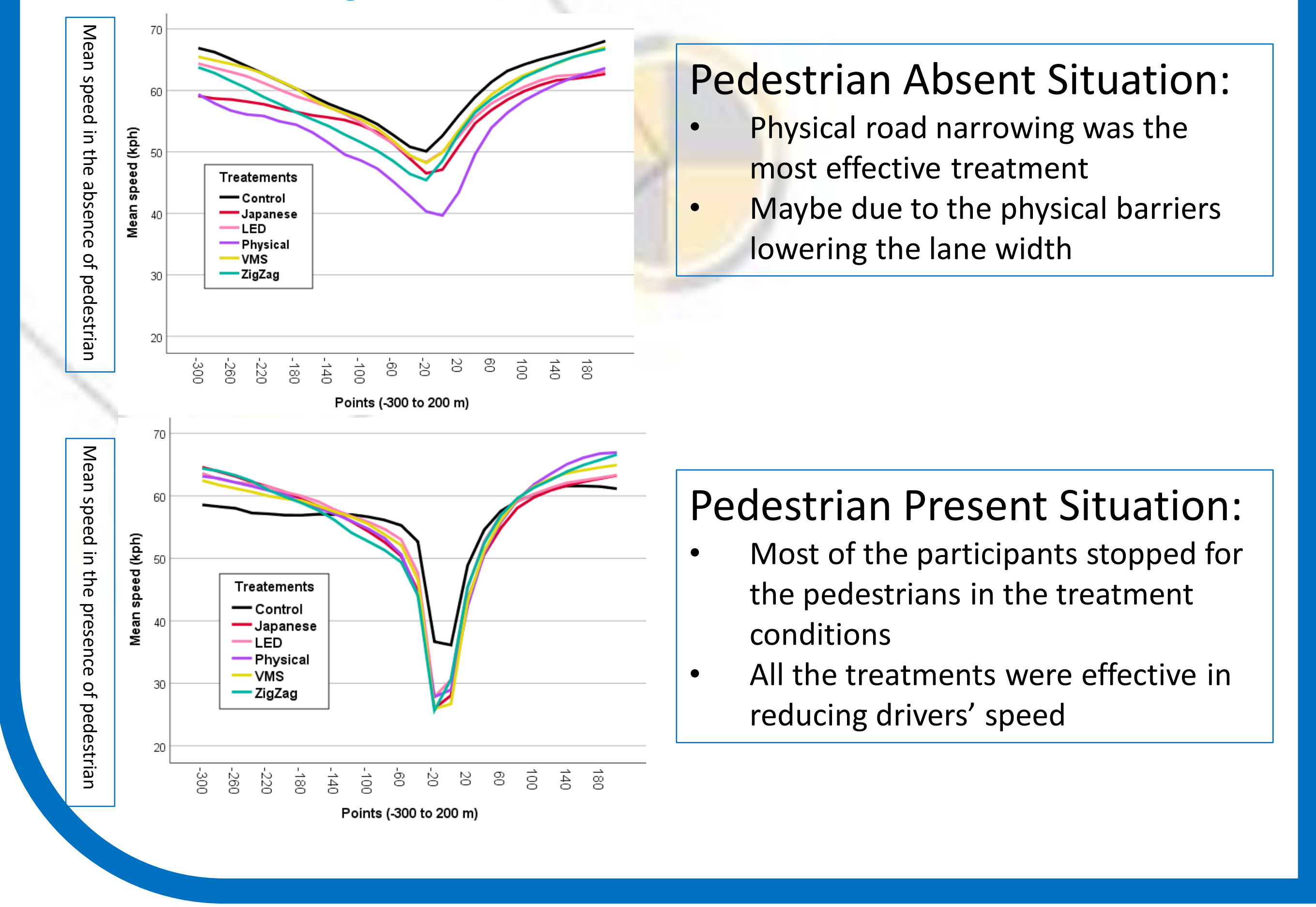

